\title{
Antiurolithiatic activity of aqueous extract of bark of moringa oleifera (lam.) in rats
}

\author{
Jameel Fahad ${ }^{1}$, Vijayalakshmi ${ }^{1}$, M. C. Satish Kumar ${ }^{1}$, Sanjeeva $^{1}$, G. Prabhath Kodancha ${ }^{1}$, \\ Benegal Adarsh ${ }^{1}$, A. L. Udupa ${ }^{2^{*}}$, U. P. Rathnakar ${ }^{3}$ \\ ${ }^{1}$ Department of pharmacology, Kasturba Medical College, Manipal, India \\ ${ }^{2}$ Department of Pharmacology, Faculty of Medical Sciences, University of the West Indies, Cave Hill, Barbados; \\ aludupa2002@yahoo.com \\ ${ }^{3}$ Department of pharmacology, Kasturba Medical College, Mangalore, Karnataka, India
}

Received 8 January 2010; revised 20 February 2010; accepted 22 February 2010.

\begin{abstract}
In the present study, aqueous extract of bark of Moringa oleifera administered orally, was evaluated for its antiurolithiatic potential in albino rats of Wistar strains. The stones were produced in this study by zinc disc foreign body insertion in the bladder supplemented with $1 \%$ ethylene glycol in drinking water. The reduction in weight of the stones was used as criteria for assessing the preventive or curative antiurolithiatic effect of the bark of this plant. Two doses of extract for prophylactic and curative groups were used. In both groups the oral administration of the extract of bark of Moringa oleifera has resulted in significant reduction in the weight of bladder stones compared to the control group.
\end{abstract}

Keywords: Moringa oleifera bark; Antiurolithiatic activity; Introduction

\section{INTRODUCTION}

Moringa oleifera is an important medicinal herb, belonging to the family Moringaceae. It is considered as miracle tree as all the parts of the plant are useful for human health. It is also known as drum stick tree, horseradish tree, clarifier tree and mother's best friend in different parts of the world, based on their appearance and unique uses. It is mostly cultivated all over the plains of India, in the old world tropics and it is used medicinally in Guinea, Madagascar, and Burma [1-3].

The various parts of the plant used include flower, pod, leaves, bark and roots. The flowers, after cooking, are eaten either mixed with other foods or fried in butter and have been shown to be rich in potassium and calcium [4]. The leaves are eaten as greens, in salads, in vegetable curries, as pickles and for seasoning. The Bark is regarded as an antiscorbic, and it exudes a reddish gum sometimes used for the treatment of diarrhoea. The roots are bitter, act as a tonic to the body and lungs, and have an expectorant activity. They are a mildly diuretic and are used as a stimulant in paralytic afflictions, epilepsy and hysteria. The pods are the most valued and widely used of all the tree parts. The pods are extremely nutritious, containing all the essential amino acids along with many vitamins and other nutrients. The immature pod can be eaten raw or prepared like green peas or green beans, while the mature pods are usually fried and possess a peanut-like flavour. The pods also yield $38-40 \%$ of non-drying, edible oil known as Ben Oil which is clear, sweet and odourless, and never becomes rancid. Overall, its nutritional value most closely resembles olive oil [4].

In recent decades, many scientific studies using the extracts of leaves, pods and roots of Moringa oleifera are being carried out to confirm many potential uses including wound healing [5,6], anti-tumour [7], antihepatotoxic [8], antifertility [9], hypotensive [10], antiurolithiatic [11] acute anti-inflammatory [6,12,13], and analgesic activity [14].

Even though the root extracts of Moringa oleifera have been studied for diuretic activity [11], there is no scientific study showing antiurolithiatic activity of Moringa oleifera bark extract. Therefore this study was conducted in order to evaluate its antiurolithiatic activity in rats.

\section{MATERIALS AND METHODS}

\subsection{Approval for the Project}

Approval for the experiment was obtained from the Institutional animal ethics committee (IAEC), Kasturba Medical College, Manipal, vide letter No. IAEC/KMC 07/2008-2009. 


\subsection{Plant Material}

The bark of Moringa oleifera Lam. available locally were collected between February and May in and around Udupi. The botanical identity has been confirmed by department of botany, Sri Poornapagna College, Udupi. The voucher specimen is preserved in our laboratory for future reference.

\subsection{Method of Extraction}

The fresh bark collected were cut into small pieces, partially crushed and soaked in water overnight which was later subjected to boiling for 6 hours. The resultant extract was then drained and concentrated in a water bath to get the concentrated extract. The yield of the extract was $10.5 \%$. The extract was stored in desiccators and used for further experiments after dissolving it in distilled water.

\subsection{Animals}

Inbred albino rats of Wistar strain, of either sex, aged around 2 to 3 months and weighing 150-200 g were used. They were housed in standard conditions of temperature $\left(25 \pm 2^{\circ} \mathrm{C}\right)$, relative humidity of $45-55 \%$, and maintained on 12-hour light: 12-hour dark cycle in animal house of Kasturba Medical College, Manipal. They were fed standard pellet diet (Hindustan Lever rat pellets) and water ad libitum.

\section{ACUTE TOXICITY STUDY}

The aqueous extract of Moringa oleifera bark was administered orally in the escalating dosages, up to $8 \mathrm{~g} / \mathrm{kg}$ to different groups of rats ( $n=6$, in each). The animals were observed for behavioural and physiological variations initially continuously for 4 hours, followed by $4^{\text {th }}$ hourly for 12 hours and there after once daily for 14 days.

\subsection{Antiurolithiatic Study: Method of Induction of Urolithiasis by Insertion of Zinc Disc [15-19]}

Rats were anaesthetized with intraperitoneal ketamine (50 mg/kg). A suprapubic incision was made and the abdomen was opened. The urinary bladder was then carefully exposed and the urine in the bladder was aspirated with a sterile syringe. A small nick was made at the apex end of urinary bladder and the sterile zinc disc (previously weighed) was carefully inserted into the bladder. Then the bladder was closed in a single stitch using chromic catgut (4-0). The abdomen was then closed in layers with chromic catgut and skin was closed with silk thread. The rats were allowed to recover from anaesthesia. Food and 1\% ethylene glycol in water was given ad libitum. The stone was allowed to form and grow inside the bladder during the study period. After the study period the rats were sacrificed and zinc disc implants/stones were removed from the bladder and dried. Stones taken out were weighed. The difference between initial and final weights indicated the amount of stone formed.

\subsection{Grouping of Animals for Different Treatments and Procedure of the Study}

Adult albino rats of Wistar strain, weighing between 150-200 g, were selected for the study. In this study using aqueous extract of bark of Moringa oleifera, the rats were divided into 6 groups with 6 animals in each group receiving different treatments. Group I-Prophylactic control (1\% ethylene glycol for 4 weeks), Group II-Prophylactic treatment ( $1 \%$ ethylene glycol+aqueous extract of bark of Moringa oleifera $400 \mathrm{mg} / \mathrm{kg}$ orally for 4 weeks), Group III-Prophylactic treatment (1\% ethylene glycol+aqueous extract of bark of Moringa oleifera $800 \mathrm{mg} /$ kg orally for 4 weeks), Group IV-Curative control (1\% ethylene glycol for 4 weeks followed by water for 4 weeks), Group V-Curative treatment (1\% ethylene glycol for 4 weeks followed by aqueous extract of bark of Moringa oleifera $400 \mathrm{mg} / \mathrm{kg}$ for 4 weeks), Group VICurative treatment (1\% ethylene glycol for 4 weeks followed by aqueous extract bark of Moringa oleifera $800 \mathrm{mg} / \mathrm{kg}$ for 4 weeks).

Prophylactic activity against urolithiasis was tested using Groups I to III in this study and after 4 weeks, animals were sacrificed and vesical calculi were collected, weighed and statistically evaluated.

Curative property was tested in using Groups IV to VI in the study and, at the end of eight weeks, animals were sacrificed and vesical calculi were collected, weighed and statistically evaluated.

\subsection{Weight of Stones}

The difference between the weight of the implanted zinc discs at the time of implantation and final weight of the dried calculi taken out from the bladder at the end of the $4^{\text {th }}$ and $8^{\text {th }}$ week period indicated the weight of deposited stone.

\section{STATISTICAL ANALYSIS}

The data obtained from the study was statistically evaluated using a parametric test ANOVA (Analysis of Variance) and Tukey as post hoc test. This was done with SPSS (Statistical package for social science) software.

\section{RESULTS}

The results of different groups studied using aqueous 
Table 1. Weight of stone material deposit on zinc discs in control and after using aqueous extract of bark of Moringa oleifera $400 \mathrm{mg} / \mathrm{kg} \& 800 \mathrm{mg} / \mathrm{kg}$ treated rats.

\begin{tabular}{lcc}
\hline \multicolumn{1}{c}{ Groups } & No.of rats & $\begin{array}{c}\text { Weight of stone }(\mathrm{mg}) \\
\text { (Mean } \pm \text { SEM) }\end{array}$ \\
\hline $\begin{array}{l}\text { Group I-prophylactic control } \\
\text { Group II-prophylactic treat- }\end{array}$ & 6 & $278.16 \pm 7.35$ \\
$\begin{array}{l}\text { ment (400 mg/kg) } \\
\text { Group III-prophylactic treat- } \\
\text { ment (800 mg/kg) }\end{array}$ & 6 & $139.5 \pm 8.89^{*}$ \\
$\begin{array}{l}\text { Group IV-curative control } \\
\begin{array}{l}\text { Group V-curative treatment } \\
(400 \mathrm{mg} / \mathrm{kg})\end{array}\end{array}$ & 6 & $269 \pm 10.45$ \\
$\begin{array}{l}\text { Group VI-curative treatment } \\
(800 \mathrm{mg} / \mathrm{kg})\end{array}$ & 6 & $170.6 \pm 12.98^{*}$ \\
\hline
\end{tabular}

${ }^{*} \mathrm{p}<0.001, \mathrm{df}=2, \mathrm{SEM}=$ Standard error of mean, $\mathrm{n}=6$

extract of bark of Moringa oleifera $400 \mathrm{mg} / \mathrm{kg} \& 800 \mathrm{mg} /$ $\mathrm{kg}$ are shown in Table 1. In this study, the extracts from bark of the plant showed significant decrease in the weight of stones compared to control after the study period.

\section{DISCUSSIONS}

In the present study, aqueous extract of bark of Moringa oleifera $400 \mathrm{mg} / \mathrm{kg} \& 800 \mathrm{mg} /$ were evaluated for the antiurolithiatic potential in albino rats of Wistar strains. The method used for induction of stones in this study was zinc disc foreign body insertion technique supplemented with $1 \%$ ethylene glycol, which is commonly used in these type of studies.

In this study, the weight of the stones was used as criteria for assessing the preventive or curative effect of the bark of Moringa oleifera. Two doses of extract for prophylactic and curative groups were used. In both groups the administration of the extract have resulted in significant $(p<0.01)$ reduction in the weight of stones compared to the control group.

The decrease in the bladder stone formation was inconsistent with the increase in the dose of the extract which could be due to variability in the response due to physiological variation. The stone formation in the control group itself was variable to a certain extent ranging from $240 \mathrm{mg}$ to $300 \mathrm{mg}$ in prophylactic control group and $248 \mathrm{mg}$ to $310 \mathrm{mg}$ in curative control group, which is indicative of normal physiological variation. Among the different strains of rats used for preclinical studies, Wistar rats are much less susceptible to persistent bladder infection and struvite stone formation in comparison to other strains. In a study where female Fischer 344 (F344), Lewis (LEW), Sprague-Dawley (SD), and Wistar (WIS) rats were inoculated with a host-adapted strain of Ureaplasma parvum, and necropsied at 2 weeks post inoculation; $100 \%$ of F344, 42\% of SD, 10\% of LEW, and $10 \%$ of WIS rats remained infected. Severe bladder lesions and struvite calculi were seen in 64\% of F344 rats; in other rat strains, bladder lesions were mild or absent [20].

\section{CONCLUSIONS}

In conclusion we can confidently confirm the possibility of antiurolithiatic activity of bark of Moringa oleifera as there was reduction in size of the stones. Further studies are needed to prove the stone dissolving property of aqueous extract of bark of Moringa oleifera $(400 \mathrm{mg} / \mathrm{kg}$ $\& 800 \mathrm{mg} / \mathrm{kg}$ ) in other animal models

\section{ACKNOWLEDGEMENT}

We the authors are thankful to the Dean of Kasturba Medical College, Manipal and to the K.M.C. Trust Manipal for the financial support rendered for this study.

\section{REFERENCES}

[1] Basu, B.D. and Kirtikar, K.R. (1980) Indian Medicinal Plants, second edn, Bishen Singh Mahendra Pal Singh, Dehradun, 1, 676-683.

[2] Nadkarni, A.K. (2002) K.M.Nadkarni's Indian Materia Medica, Popular prakashana, Bombay, $3^{\text {rd }}$ edition, 1, 811-816.

[3] Vaidyaratnam, P.S.V. (1994) Indian Medicinal Plants-A Compendium of 500 Species. Orient Longman Ltd., Madras, 4, 59-64.

[4] Fahey, J.W. (2005) Moringa oleifera: A Review of the Medical Evidence for Its Nutritional, Therapeutic, and Prophylactic Properties. Part 1. Trees for Life Journal, December, 1(5).

[5] Udupa, S.L., Udupa, A.L. and Kulkarni, D.R. (1994) Studies on the anti-inflammatory and wound healing properties of Moringa oleifera and Aegle marmelos, Fitoterapia, 65, 119-123.

[6] Udupa, S.L., Udupa, A.L. and Kulkarni, D.R., (1998) A comparative study on the effect of some indigenous drugs on normal and steroid-depressed healing. Fitoterapia, 69, 507-510.

[7] Guevara, A.P., Vargas, C. and Uy, M. (1996) Anti-inflammatory and antitumor activities of seed extracts of malunggay, Moringa oleifera L. (Moringaceae), Philippine Journal of Science, 125, 175-184.

[8] Ruckmani, K., Kavimani, S., Anandan, R. and Jaykar, B, (1998) Effect of Moringa oleifera Lam. on paracetamol induced hepatotoxicity, Indian Journal of Pharmaceutical Science, 60, 33-35.

[9] Prakash, A.O., Pathak, S., Shukla, S. and Mathur, R. (1988) Pre and post-implantation changes in the uterus of rats: Response to Moringa oleifera Lam. extract, Ancient Science of Life, 8, 49-54.

[10] Faizi, S., Siddiqui, B.S., Saleem, R., Siddiqui, S., Aftab, K. and Gilani, A.H. (1995) Fully acetylated carbamate 
and hypotensive thiocarbamate glycosides from Moringa oleifera. Phytochemistry, 38, 957-963.

[11] Ravindra, V.K., Navneet, B.G., Alagawadi, K.R. and Rudraprabhu, V.S. (2006) Effect of Moringa oleifera Lam. root-wood on ethylene glycol induced urolithiasis in rats. Journal of Ethnopharmacology, 105(1-2), 306-311.

[12] Caceres A., Saravia A., Rizzo, S., Zabala, L., De Leon, E. and Nave F. (1992) Pharmacological properties of Moringa oleifera 2: Screening for antispasmodic anti-inflammatory and diuretic activity. Journal of Ethnopharmacology, 36, 233-237.

[13] Ezeamuzi, I.C., Ambakederemo, A.W., Shode, F.O. and Ekwebelem, S.C. (1996) Antiinflammatory effects of Moringa leifera root extract. Journal of Pharmacognosy, 34, 207-212.

[14] Rao, C.V., Ojha, S.K. and Mehrotra. S. (2003) Analgesic effect of Moringa oleifera leaf extract on rats, Proceedings of the Second World Congress on Biotechnologi cal Developments of Herbal Medicine Lucknow, India, 42.

[15] Marshall, L. and Stoller, M.D. (2004) Urinary stone dis- ease, in Smith’s General Urology; Emil A, Tanagho, Jack W, Aninch M. Eds., Lange medical books, 16th ed., New York, 256-291.

[16] Moe, O.W. (2006) Kidney stones: Pathophysiology and medical management. Lancet Jan, 367(9507), 333-344.

[17] Prasad, K.V.S.R.G., Sujatha, D. and Bharathi, K. (2007) Herbal Drugs in Urolithiasis-A Review. Pharmacognosy Reviews, 1(1), 175-179.

[18] Vargas, S.R. and Perez, G.R.M. (2002) Antiurolithiatic activity of Salix taxifolia aqueous extract. Pharmaceutical Biology, 40(8), 561-563.

[19] Satoh, M., Munakata, K., Kitoh, K., Takeuchi, H. and Yoshida, O. (1984) A newly designed model for infection-induced bladder stone formation in the rat. The Journal of Urology, 132(6), 1247-1249.

[20] Reyes, L., Reinhard, M., O’Donell, L.J., Stevens, J. and Brown, M.B. (2006) Rat strains differ in susceptibility to ureaplasma parvum-induced urinary tract infection and struvite stone formation. Infection and Immunity, 74(12), 6656-6664. 